\title{
2020 Korean Guidelines for Cardiopulmonary Resuscitation. Part 4. Adult advanced life support
}

Jaehoon Oh', Kyoung-Chul Cha ${ }^{2}$, Jong-Hwan Lee ${ }^{3}$, Seungmin Park', Dong-Hyeok Kim ${ }^{5}$, Byung Kook Lee ${ }^{6}$, Jung Soo Park ${ }^{7}$, Woo Jin Jung ${ }^{2}$, Dong Keon Lee ${ }^{3}$, Young II Roh ${ }^{2}$, Tae Youn $\mathrm{Kim}^{2}$, Sung Phil Chung ${ }^{8}$, Young-Min Kim ${ }^{9}$, June Dong Park ${ }^{9}$, Han-Suk Kim ${ }^{10}$, Mi Jin Lee ${ }^{11}$, Sang-Hoon $\mathrm{Na}^{12}$, Gyu Chong $\mathrm{Cho}^{13}$, Ai-Rhan Ellen $\mathrm{Kim}^{14}$, Sung Oh Hwang ${ }^{2}$; on behalf of the Steering Committee of the 2020 Korean Guidelines for Cardiopulmonary Resuscitation and Emergency Cardiovascular Care

'Department of Emergency Medicine, Hanyang University College of Medicine, Seoul, Korea ${ }^{2}$ Department of Emergency Medicine, Yonsei University Wonju College of Medicine, Wonju, Korea ${ }^{3}$ Department of Anesthesiology and Pain Medicine, Sungkyunkwan University College of Medicine, Seoul, Korea

${ }^{4}$ Department of Emergency Medicine, Seoul National University College of Medicine, Seoul, Korea ${ }^{5}$ Department of Internal Medicine, Ewha Womans University College of Medicine, Seoul, Korea ${ }^{6}$ Department of Emergency Medicine, Chonnam National University College of Medicine, Gwangju, Korea 'Department of Emergency Medicine, Chungnam National University College of Medicine, Daejeon, Korea ${ }^{8}$ Department of Emergency Medicine, Yonsei University College of Medicine, Seoul, Korea

${ }^{9}$ Department of Emergency Medicine, The Catholic University of Korea College of Medicine, Seoul, Korea

${ }^{10}$ Department of Pediatrics, Seoul National University College of Medicine, Seoul, Korea

${ }^{1}$ Department of Emergency Medicine, Kyungpook National University College of Medicine, Daegu, Korea

${ }^{12}$ Department of Internal Medicine, Seoul National University College of Medicine, Seoul, Korea

${ }^{13}$ Department of Emergency Medicine, Hallym University College of Medicine, Seoul, Korea

${ }^{14}$ Department of Pediatrics, Ulsan University College of Medicine, Seoul, Korea
elSSN: 2383-4625

Received: 7 March 2021

Revised: 7 March 2021

Accepted: 19 March 2021

Correspondence to: Kyoung-Chul Cha Department of Emergency Medicine, Yonsei University Wonju College of Medicine, 20 Ilsan-ro, Wonju 26426, Korea

E-mail: chaemp@yonsei.ac.kr ORCID

https://orcid.org/0000-0003-1818-2466

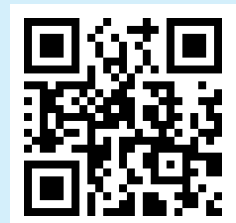

How to cite this article:

Oh J, Cha KC, Lee JH, Park S, Kim DH, Lee BK, Park JS, Jung WJ, Lee DK, Roh YI, Kim TY, Chung SP, Kim YM, Park JD, Kim HS, Lee MJ, $\mathrm{Na} \mathrm{SH}$, Cho GC, Kim AE, Hwang SO; on behalf of the Steering Committee of the 2020 Korean Guidelines for Cardiopulmonary Resuscitation and Emergency Cardiovascular Care. 2020 Korean Guidelines for Cardiopulmonary Resuscitation. Part 4. Adult advanced life support. Clin Exp Emerg Med 2021;8(S):S26-S40

https://doi.org/10.15441/ceem.21.023

This is an Open Access article distributed under the terms of the Creative Commons Attribution Non-Commercial License (https:// creativecommons.org/licenses/by-nc/4.0/). 
has also been published. ${ }^{6}$

Based on new research evidence, relevant contents of the 2015 CPR guidelines were revised in the 2020 Korean Adult ALS guidelines, with the addition of recommendations such as double sequential defibrillation, application of ultrasound, and monitoring of cerebral oxygen saturation during CPR. ${ }^{7-12}$ In particular, the establishment of a rapid response team (RRT) or medical emergency team and the application of an early warning score were emphasized for preventing in-hospital cardiac arrest (IHCA). ${ }^{13-19}$ Special- ized guidelines for the resuscitation of patients with confirmed or suspected coronavirus disease 2019 (COVID-19) have also been included. 20,21

\section{ADULT ALS ALGORITHMS}

High-quality CPR should be performed during all processes of ALS. The defibrillation pads or electrodes should be applied to the patient to monitor the electrocardiography (ECG) rhythm imme-

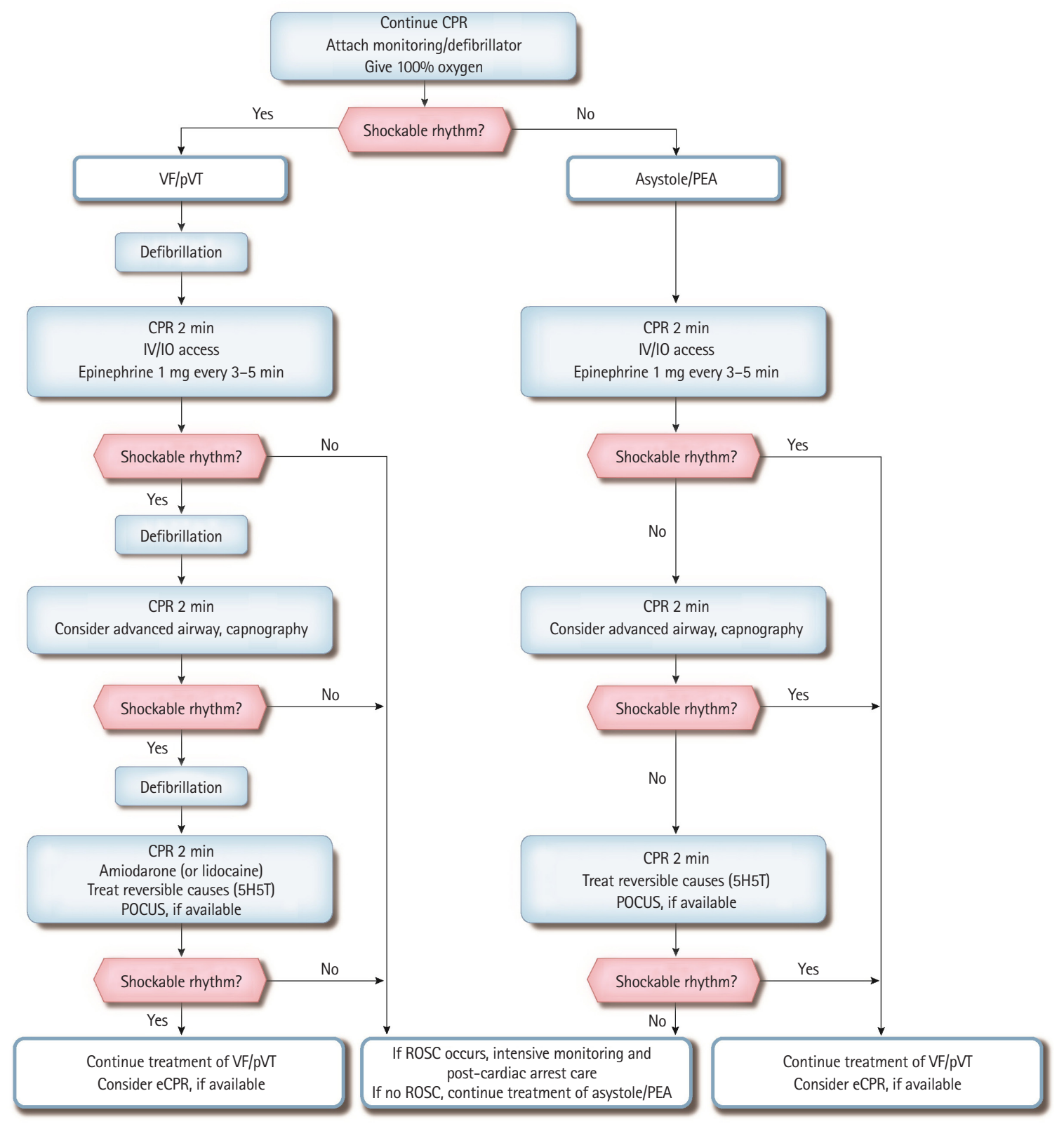

Fig. 1. Adult advanced life support algorithm for in-hospital cardiac arrest. CPR, cardiopulmonary resuscitation; VF, ventricular fibrillation; pVT, pulseless ventricular tachycardia; IV, intravenous; IO, intraosseous; PEA, pulseless electrical activity; 5H, hypovolemia, hypoxia, hyperkalemia, hydrogen ion (acidosis), and hypothermia; 5T, tension pneumothorax, tamponade (cardiac), toxin, thrombosis (pulmonary), and thrombosis (coronary); POCUS, point-of-care ultrasound; eCPR, extracorporeal cardiopulmonary resuscitation; ROSC, return of spontaneous circulation. 
diately after the ALS team arrives. Based on the ECG rhythm analysis, a team leader should decide on a treatment strategy as soon as possible. All team members should be proficient in the entire ALS algorithm so that it can be performed efficiently.

\section{Adult ALS for IHCA}

When an ALS team arrives at the scene, the defibrillation pads or electrodes should be attached to the patient to analyze the ECG rhythm immediately. To ensure high-quality CPR, newly arrived providers should perform chest compressions and ventilation in place of basic life support (BLS) providers. The chest compressionto-ventilation ratio should be $30: 2$ on 100\% oxygen if an advanced airway has not been placed. Cardiac arrest rhythms are classified as shockable rhythms (ventricular fibrillation [VF] and pulseless ventricular tachycardia [pVT]) and non-shockable rhythms (asystole and pulseless electrical activity [PEA]). If the cardiac rhythm shows as a $\mathrm{pVT}$ or PEA, ALS providers should palpate the carotid artery to confirm the absence of a pulse. Since the ECG rhythm might change during CPR, providers should analyze it every 2 minutes and follow the treatment algorithm according to the analysis (Fig. 1).

\section{Shockable rhythms (VF and pVT)}

Because VF and pVT can be terminated with defibrillation, they are also known as "shockable rhythms." Providers should deliver a single shock (biphasic wave defibrillator: 120-200 J, monophasic wave defibrillator: $360 \mathrm{~J}$ ) when a shockable rhythm is confirmed on the ECG monitor and resume CPR immediately for 2 minutes, beginning with chest compressions without a pulse check or ECG rhythm analysis. If the provider cannot identify the manufacturer's recommended dose of the biphasic defibrillator, defibrillation (shock) should be conducted at $200 \mathrm{~J}$. After the first shock is delivered, an intravenous (IV) or intraosseous (IO) route for drug administration should be established, and a 1 mg bolus of epinephrine should be administered, followed by a bolus of IV fluids. The IO route should be attempted only if the IV access is unsuccessful or not feasible. Administration of $1 \mathrm{mg}$ epinephrine should be repeated every 3 to 5 minutes while ALS continues. After 2 minutes of CPR, the ECG rhythm should be checked. If a shockable rhythm persists, the provider should deliver another shock with equivalent or higher energy than the previous defibrillation and resume CPR immediately.

Meanwhile, another provider should consider performing advanced airway management and capnography. If an advanced airway is in place, it is reasonable to deliver 1 breath every 6 seconds (10 times/min) with continuous chest compressions. If endotracheal intubation has been performed, monitoring of the end-tidal carbon dioxide $\left(\mathrm{ETCO}_{2}\right)$ can assess the CPR quality and detect ROSC. If a shockable rhythm persists after 2 minutes of $\mathrm{CPR}$, the provider should deliver another shock and resume CPR. Amiodarone or lidocaine can be prepared for refractory VF or pVT that is unresponsive to the second shock and may be administered immediately after the third shock. The recommended first dose is $300 \mathrm{mg}$ for amiodarone or 1 to $1.5 \mathrm{mg} / \mathrm{kg}$ for lidocaine. If the VF or pVT persists, a second dose of amiodarone $150 \mathrm{mg}$ or lidocaine 0.5 to $0.75 \mathrm{mg} / \mathrm{kg}$ can be administered. Based on the patient's cardiac arrest situation or medical history, immediate identification and treatment of the reversible causes of cardiac arrest may facilitate ROSC. Point-of-care ultrasound (POCUS), if available and not interfering with CPR, may be helpful to identify the cause of cardiac arrest. Extracorporeal CPR (eCPR) may be considered if ROSC is not achieved despite a high-quality CPR and if there is a potentially reversible cause of cardiac arrest that might benefit from temporary cardiorespiratory support.

\section{Non-shockable rhythms (asystole and PEA)}

As asystole and PEA do not require defibrillation during CPR, they are referred to as "non-shockable rhythms." Asystole is the absence of ventricular contraction regardless of the presence of atrial contraction. Meanwhile, PEA is a clinical condition defined by the absence of measurable blood pressure and palpable pulse despite the presence of sufficient electrical discharge and a heterogeneous group of pulseless rhythms, including pseudo-electromechanical dissociation, idioventricular rhythms, ventricular escape rhythms, and brady-asystolic rhythms. Patients with cardiac arrest with PEA can be treated if the reversible causes are identified and corrected, even though the survival rate of cardiac arrest patients with asystole is very low. If the ECG rhythm is nonshockable, chest compressions should be performed immediately for 2 minutes while the route (IV or IO) for drug administration is being established. Subsequently, a $1 \mathrm{mg}$ bolus of epinephrine should be administered as soon as possible, along with an IV fluid push. Administration of $1 \mathrm{mg}$ of epinephrine should be repeated every 3 to 5 minutes while ALS continues. After 2 minutes of CPR, the ECG rhythm should be analyzed. If the asystole or PEA persists, chest compressions should be continued, and advanced airway management should be performed. If a shockable rhythm is observed, the shock should be delivered according to the "shockable rhythm" algorithm. POCUS, if available and not interfering with CPR, can be helpful to identify the cause of cardiac arrest.

\section{Adult ALS for OHCA}

The adult ALS algorithm for OHCA is similar to that for IHCA. However, in OHCA, bag-mask ventilation (BMV) is preferably recom- 


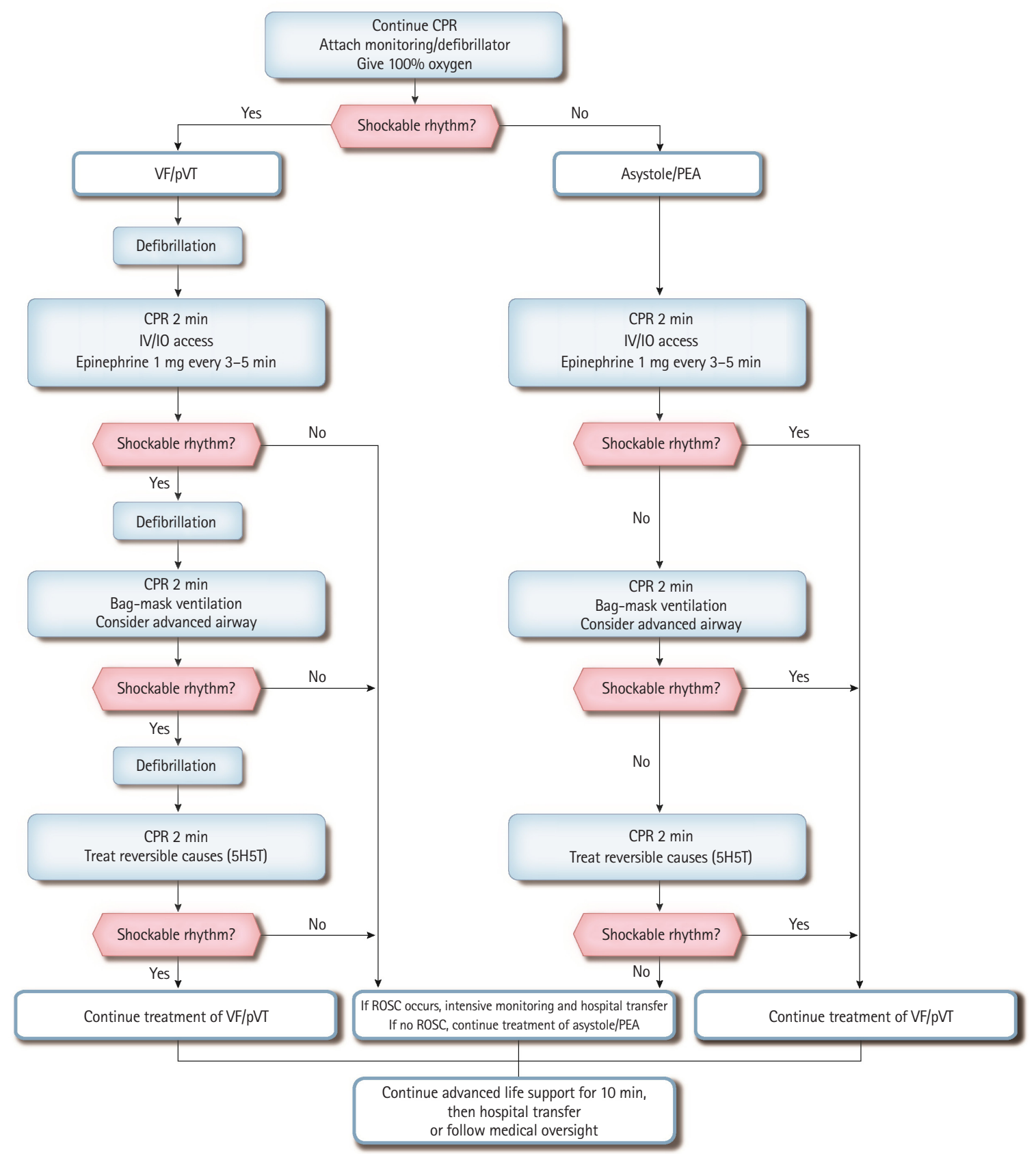

Fig. 2. Adult advanced life support algorithm for out-of-hospital cardiac arrest. CPR, cardiopulmonary resuscitation; VF, ventricular fibrillation; $p V T$, pulseless ventricular tachycardia; PEA, pulseless electrical activity; IV, intravenous; IO, intraosseous; 5H, hypovolemia, hypoxia, hyperkalemia, hydrogen ion (acidosis), and hypothermia; 5T, tension pneumothorax, tamponade (cardiac), toxin, thrombosis (pulmonary), and thrombosis (coronary); ROSC, return of spontaneous circulation.

mended for providers who are unfamiliar with advanced airway management. Using an SGA device is also preferred to endotracheal intubation for providers with little experience in endotracheal intubation. It is recommended to consider transferring the patient to the hospital after performing ALS on scene for $10 \mathrm{~min}-$ utes if the emergency medical technicians (EMTs) participating in the resuscitation could perform ALS, including advanced airway management and epinephrine administration. In contrast, it is recommended to transfer the patient to the hospital after resuscitation for 6 minutes according to the BLS guidelines if the prehospital resuscitation team could not perform ALS. For example, in the case of a multitiered dispatch system, if the first EMT who arrives at the scene can perform ALS, the EMT should consider transferring the patient to the hospital after providing ALS for 10 


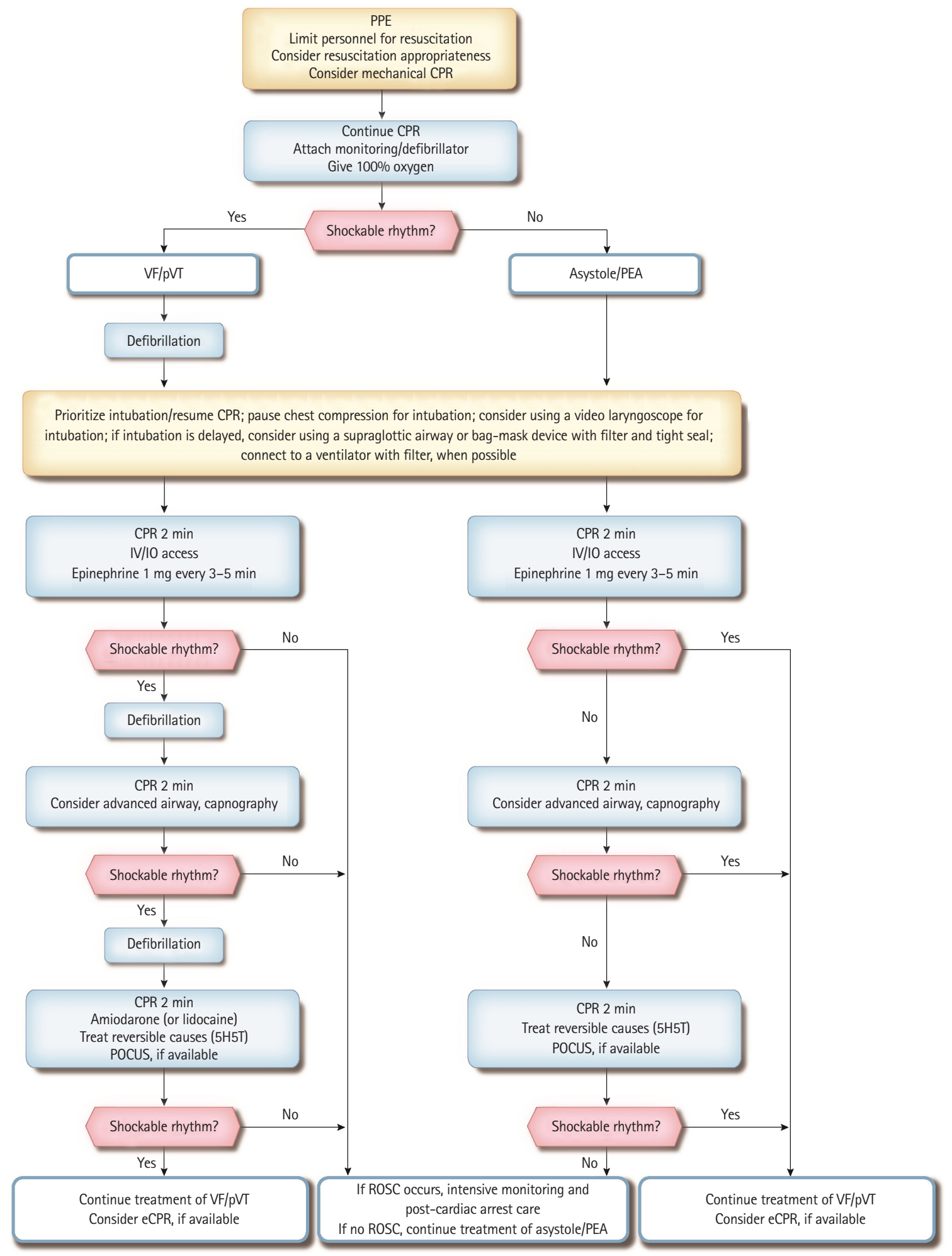

Fig. 3. Adult advanced life support for cardiac arrest during the COVID-19 outbreak. PPE, personal protective equipment; CPR, cardiopulmonary resusci-

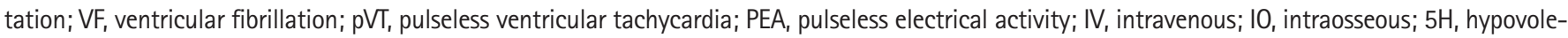
mia, hypoxia, hyperkalemia, hydrogen ion (acidosis), and hypothermia; $5 T$, tension pneumothorax, tamponade (cardiac), toxin, thrombosis (pulmonary), and thrombosis (coronary); POCUS, point-of-care ultrasound; eCPR, extracorporeal cardiopulmonary resuscitation; ROSC, return of spontaneous circulation. 
minutes; otherwise, providing 6 minutes of CPR and then transferring the patient to the hospital would be appropriate. Scene time interval could be modified under direct medical oversight (Fig. 2).

\section{Adult ALS for cardiac arrest during the COVID-19 outbreak}

Chest compressions, positive pressure ventilation, and securing an advanced airway can generate aerosols, which could increase the risk of transmission of COVID-19. It is essential that providers protect themselves and their colleagues from unnecessary exposure to both airborne and droplet particles. Members of the ALS team should wear appropriate personal protective equipment (PPE) with a minimum of Level D protection, including a mask (a minimum of N95 or FFP3) or powered air-purifying respirator, gloves, gown, and goggles or face shield before starting ALS. For patients with a poor prognosis, the provision of resuscitation should be reevaluated, and ALS should be started when resuscitation is deemed necessary. The ALS team should comprise the minimum number of essential personnel. A mechanical CPR device can be used to minimize contact with the patient. For ECG rhythm check and defibrillation, a defibrillation pad should be used, if feasible. If advanced airway management is required, the provider should stop the chest compressions, perform endotracheal intubation with a cuffed tube, and connect the endotracheal tube with a high-efficiency particulate air filter, if available. Video laryngoscopy for endotracheal intubation should also be considered to reduce exposure to aerosol. If endotracheal intubation is delayed, the provider should consider attaching an SGA device or bag-valve mask to a high-efficiency particulate air filter with a tight seal. After completion of resuscitation, PPE should be disposed of according to the infection control guidelines and ALS providers should wash their hands thoroughly with soap and water or disinfect them with alcohol-based hand sanitizer as soon as possible, followed by a change of clothes (Fig. 3).

\section{RECOMMENDATIONS FOR ADULT ALS}

\section{Feedback device and monitoring during ALS}

Using a feedback device and monitoring the patient can help optimize CPR quality and assess patient status during CPR. ${ }^{22}$ However, it is not recommended to implement real time CPR feedback devices routinely because their use has no significant effect on resuscitation outcome compared with not using them at all. ${ }^{23-26}$ Nevertheless, real time CPR feedback devices in medical systems can be used for monitoring CPR quality. No studies have proven the usefulness of checking the pulse to evaluate the effectiveness of chest compressions during CPR. However, the pulse can be checked as a method to confirm ROSC. Providers should check the pulse within 5 to 10 seconds to minimize chest compression interruption and, if there is no pulse, resume chest compressions immediately. ${ }^{27-29}$ Advanced monitoring parameters such as $\mathrm{ETCO}_{2}$ partial pressure, coronary perfusion pressure, and central venous oxygen saturation can be used as physiological monitoring indices during ALS. During cardiac arrest, $\mathrm{ETCO}_{2}$ levels reflect the cardiac output generated by chest compressions. $\mathrm{An}^{\mathrm{ETCO}_{2}}$ level of $<10 \mathrm{mmHg}$ despite high-quality CPR of $>20$ minutes has been associated with an extremely poor chance of ROSC and survival outcome. An abrupt increase of $\mathrm{ETCO}_{2}$ during resuscitation may imply ROSC ${ }^{30-34}$ However, $\mathrm{ETCO}_{2}$ partial pressure should not be used as a sole indicator of CPR quality and ROSC.

Measuring the $\mathrm{ETCO}_{2}$ level from an SGA or bag-valve-mask airway cannot adequately predict the efficiency of chest compressions and resuscitation outcomes, but it is the most reliable method for confirming the correct placement of an endotracheal tube after intubation. ${ }^{35}$ If the coronary perfusion pressure is $<15$ mmHg during CPR, the chance of ROSC is low. ${ }^{36}$ However, coronary perfusion pressure is difficult to monitor because it is calculated from the arterial relaxation "diastolic" pressure and central venous pressure during CPR. If the central venous oxygen saturation $\left(\mathrm{ScVO}_{2}\right)$ has been monitored prior to cardiac arrest, or if catheterization is possible without interfering with resuscitation, providers can consider measuring the $\mathrm{Scv}_{2}$ to monitor $\mathrm{CPR}$ quality. Studies have shown that a $\mathrm{ScvO}_{2}$ of $<30 \%$ during CPR is associated with failure to restore spontaneous circulation; thus, providers should ensure high-quality CPR to maintain the $\mathrm{ScvO}_{2}$ above $30 \% .^{37}$

Pulse oximetry is not a suitable monitoring method because peripheral circulation is insufficient during cardiac arrest. Nevertheless, it can be used to evaluate proper oxygenation after ROSC. ${ }^{27}$ Moreover, regional cerebral oxygen saturation monitoring using near-infrared spectroscopy during adult CPR can be easily applied noninvasively to help assess cerebral perfusion status and predict ROSC and prognosis. ${ }^{11,38}$

\section{Vascular access for drug administration in cardiac arrest} When performing high-quality CPR and defibrillation, providers should be able to establish a route for drug administration. This procedure should not interfere with chest compressions. ${ }^{39,40}$ The peripheral IV route is the traditional approach; it is reasonable that providers should first attempt IV access for drug administration during CPR. ${ }^{41,42}$ A fluid bolus of $20 \mathrm{~mL}$ should be injected after drug administration to promote the entry of drugs into the central circulation. Lifting the arm during or after drug injection 
might theoretically promote the inflow of drug into the central circulation by gravity, although there is no evidence to support this. 10 access, on the other hand, is safe and useful for infusion of fluids, administration of drugs, and blood sampling in patients of any age. However, two studies have shown that the rates of ROSC and survival to hospital discharge were lower with using 10 access than with using IV access during cardiac arrest. ${ }^{40,43} \mathrm{IO}$ access may nonetheless be considered if IV access is unsuccessful or not feasible. Another option is drug administration via a central venous catheter, which can achieve higher peak concentrations and more rapid circulation than peripheral IV administration. ${ }^{44-46}$ Such a route may be considered by skilled providers when IV and IO access are unsuccessful or not feasible, although it may require interruption of $\mathrm{CPR}$. An endotracheal tube may also be used, but drug delivery and pharmacological effects can be unpredictable with this route. ${ }^{47,48}$

\section{Medications during cardiac arrest Vasopressors}

The alpha-adrenergic effect of epinephrine increases coronary artery perfusion pressure and cerebral perfusion pressure during CPR. In a study comparing the effects of epinephrine and placebo in patients with $\mathrm{OHCA}$, the 3-month survival rate was higher in the group administered $1 \mathrm{mg}$ of epinephrine at intervals of 3 to 5 minutes. ${ }^{4}$ Therefore, it is recommended to administer $1 \mathrm{mg}$ of epinephrine at intervals of 3 to 5 minutes to patients with cardiac arrest regardless of the cardiac arrest rhythm. Other studies with a very low level of evidence showed that high-dose epinephrine administration improved spontaneous circulation and survival to hospital admission compared with standard-dose administration (1 mg every 3 to 5 minutes in the form of a 1:1,000 ampule or 1:10,000 prefilled syringe formula) but did not improve survival to hospital discharge and neurological outcomes. ${ }^{49,50}$ Therefore, routine administration of high doses of epinephrine is not recommended; however, an expert may deem it necessary. ${ }^{51}$

The non-adrenergic peripheral vasoconstrictor, vasopressin, can also augment arterial blood pressure. A study comparing the effects of epinephrine and vasopressin found no difference in prognosis in patients with OHCA. ${ }^{52,53}$ No differences were also found in the resuscitation outcomes in trials comparing vasopressin alone or vasopressin combined with epinephrine to epinephrine alone in cardiac arrest patients..$^{54,55}$ However, no studies have shown that the use of vasopressin alone or in combination with epinephrine worsens the prognosis of cardiac arrest patients. ${ }^{52-56}$ Therefore, 40 units of vasopressin or vasopressin in combination with epinephrine may be administered as an alternative for the first or second dose of epinephrine.

\section{Antiarrhythmic drugs}

Administration of amiodarone or lidocaine to OHCA patients with refractory VF or pVT improved survival to hospital admission but did not improve overall survival to hospital discharge or survival with good neurological outcome. The critical outcome of survival to hospital discharge was improved with amiodarone or lidocaine compared to placebo in patients with bystander-witnessed cardiac arrest; however, there was no difference between amiodarone and lidocaine with regard to ROSC, favorable neurological outcome, or survival to hospital discharge. ${ }^{5}$ Additionally, the routine use of magnesium is not recommended in adult cardiac arrest patients. ${ }^{57}$ When using amiodarone, the first dose is $300 \mathrm{mg} \mathrm{IV}$ or IO, and 150 $\mathrm{mg}$ can be added if the patient remains unresponsive. The first dose of lidocaine is 1 to $1.5 \mathrm{mg} / \mathrm{kg} \mathrm{IV}$ or IO bolus, and then 0.5 to $0.75 \mathrm{mg} / \mathrm{kg}$ every 5 to 10 minutes; up to $3 \mathrm{mg} / \mathrm{kg}$ can be added. ${ }^{57,58}$ Although lidocaine or beta-blockers may be considered for the prevention of arrhythmias immediately after ROSC in patients with refractory VF or pVT, their effectiveness remains uncertain. . $^{59,60}$

\section{Defibrillation}

Early defibrillation is crucial in patients with VF or pVT. Therefore, providers should deliver a shock immediately when the defibrillator is ready and a shockable rhythm is detected on ECG. ${ }^{61-65} \mathrm{Bi}-$ phasic waveform defibrillators are preferred over monophasic defibrillators because they are more safe and effective. ${ }^{66,67}$ In unmonitored cardiac arrest, a single-shock strategy is suggested because the success rate of the first shock is around 90\% and chest compression interruption is prolonged in stacked shocks. ${ }^{68,69}$ Chest compressions should be performed even while the defibrillator is charging. The chest compression interruption before and after defibrillation should be within $10 \mathrm{~s}$ during the entire process of resuscitation. ${ }^{70-73}$ For effective defibrillation, the shock should be delivered at the end of expiration to decrease transthoracic resistance, and it would be better to use defibrillation pads rather than paddles to ensure contact with the chest pads. ${ }^{74-76}$ The usefulness of double sequential defibrillation for refractory VF or pVT has not been established. ${ }^{9,77}$

\section{Advanced airway management for resuscitation}

Providers may use either BMV or an advanced airway strategy during ALS. However, in the case of advanced airway management in OHCA, EMTs without adequate training and experience in endotracheal intubation should use an SGA device. It is recommended that only experienced EMTs should try to perform endotracheal intubation. ${ }^{78-83}$ For adult patients with IHCA, either an SGA device or endotracheal intubation may be considered. 


\section{Use of mechanical chest compression devices}

The use of mechanical chest compression devices has not shown improvement in the critical outcomes in OHCA and IHCA. ${ }^{84-90}$ However, the use of these devices may be considered in specific settings where high quality manual compressions are not possible or may harm the providers (e.g., limited personnel, in a moving ambulance, during coronary angiography, during prolonged CPR, during eCPR, or risk of exposure to infectious disease such as $\mathrm{CO}$ VID-19). ${ }^{20,91}$

\section{eCPR}

eCPR refers to venoarterial extracorporeal membrane oxygenation and cardiopulmonary bypass during the resuscitation of a cardiac arrest patient. Providers can consider applying eCPR to patients who have not achieved spontaneous circulation or have experienced repeated cardiac arrests despite receiving high quality CPR and patients who are expected to have a good neurological outcome. Highly trained medical staff and proper equipments and facilities are necessary for successful application of extracorporeal membrane oxygenation. ${ }^{92,93} \mathrm{eCPR}$ is recommended in patients aged $<75$ years and those with an initially shockable rhythm, a cardiac etiology or reversible cause of cardiac arrest, a no-flow time of $<5$ minutes, an unsuccessful resuscitation despite receiving ALS for $>10$ minutes, and a total collapse time of $<60 \mathrm{~min}-$ utes..$^{94-107}$

\section{ADDITIONAL CONSIDERATIONS DURING ALS}

\section{Proper oxygen and carbon dioxide targets during CPR and after ROSC}

Based on previous CPR guidelines suggesting that a high oxygen level must be supplied during CPR and a study finding that the arterial partial pressure of oxygen was higher in resuscitated patients, it is recommended to supply 100\% oxygen during CPR. ${ }^{108}$ However, after ROSC, it is necessary to adjust the level of inhaled oxygen to maintain an oxygen saturation of $94 \%$ to $98 \%$. $^{109-111}$ There is insufficient evidence for or against targeting mild hypercapnia compared with normocapnia in postcardiac arrest patients. ${ }^{109,110}$

\section{Factors for predicting outcomes during CPR}

Since the $\mathrm{ETCO}_{2}$ level reflects the cardiac output generated by chest compressions, it could be used to predict the patient's out-

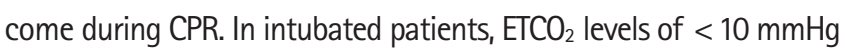
after 20 minutes of ALS were associated with poor outcomes, which can be a factor for deciding on whether to terminate resuscitation. ${ }^{32,112}$ However, this parameter should not be used alone as a prediction tool for terminating resuscitation during CPR and should not be applied to patients who have not undergone endotracheal intubation.

\section{Application of ultrasonography during CPR}

Experienced physicians can use an ultrasound, if it does not interfere with $\mathrm{CPR}$, to diagnose reversible causes of cardiac arrest such as cardiac tamponade, pulmonary thromboembolism (PTE), and myocardial infarction as well as to identify the existence of cardiac motility in patients with a PEA rhythm..$^{10,113-115}$ Ultrasound can also be used as an alternative to $\mathrm{ETCO}_{2}$ capnography to confirm the correct placement of an endotracheal tube during CPR. ${ }^{116}$ However, it should not be recommended as an independent predictor for terminating resuscitation.

\section{PTE}

Cardiac arrest due to PTE is the most dangerous complication of venous thromboembolism, and most cases of PTE are caused by deep vein thrombosis. ${ }^{117}$ There is evidence of low certainty supporting the occurrence of intra-arrest thrombolysis in patients suspected with PTE. ${ }^{118-120}$ There is also evidence of very low certainty supporting the performance of surgical embolization or percutaneous mechanical thrombectomy to resuscitate patients with cardiac arrest. ${ }^{121}$ Therefore, thrombolysis is recommended in cardiac arrest patients suspected of PTE. Providers should also consider performing surgical embolectomy or percutaneous mechanical embolectomy in cardiac arrest patients diagnosed with PTE.

\section{Cardiac arrest in pregnancy}

In pregnant women over 20 weeks of gestation, the cardiac output might be decreased by $30 \%$ to $40 \%$ as a result of compression of the inferior vena cava and aorta by the uterus, which reduces venous return. ${ }^{122}$ In this case, the effectiveness of chest compressions may be reduced. The easiest method to avoid compressing the inferior vena cava or aorta is by lateral uterine displacement, which can be achieved by placing the patient in a supine position on a firm surface and moving the uterus to the patient's left by pushing it with one hand from the right side or pulling it with two hands from the left side. ${ }^{123,124}$

When providing chest compressions, the provider may consider placing the chest compressions slightly higher than the center of the sternum, which is the standard position, to take account of the rise of the abdominal cavity and diaphragm during pregnancy. ${ }^{125,126}$ However, there is still insufficient evidence about the proper positioning of chest compressions in pregnancy. Since there is no change in transthoracic impedance during pregnancy 
and there are no reports that defibrillation affects the fetal heart, defibrillation can be performed according to standard CPR guidelines.

If cardiac arrest is imminent or occurs in pregnant women, hysterotomy or cesarean section should be performed as soon as possible. Early delivery can improve the resuscitation outcomes by relieving compression of the aorta and vena cava. ${ }^{127}$ Several studies of pregnant women with cardiac arrest showed that fetal survival rates were high when the cesarean section was performed successfully within 5 minutes of cardiac arrest. ${ }^{128}$ Therefore, it is recommended to perform a cesarean section within 5 minutes when spontaneous circulation is not achieved even after performing CPR for the first 4 minutes in pregnant women who are at $>20$ weeks of gestation or whose uterus is palpable above the umbilicus.

\section{RRT and early warning score in IHCA}

"Early recognition and CPR team activation" constitute the first chain of survival from IHCA according to the 2000 Korean CPR guidelines. For successful resuscitation of patients with IHCA, an appropriate survival environment that includes operation of an RRT, training in ALS, establishment of a cardiac arrest treatment system, and quality improvement activities must be established. ${ }^{129-131}$

An RRT is designed to detect patients who are deteriorating rapidly at an early stage and to respond appropriately. ${ }^{13}$ The role of an RRT includes making decisions about transferring the patient to the intensive care unit, implementing a do-not-resuscitate order, performing intensive care including CPR, and planning care for a patient with terminal illness.

Most cases of IHCA exhibit a non-shockable rhythm at an early stage, which is generally preceded by respiratory failure or shock..$^{81,132,133}$ Therefore, the use of an early warning score can help the RRT detect a rapidly deteriorating patient. Hospital systems may use different early warning scores, but the NEWS (National Early Warning Score) and MEWS (Modified Early Warning Score) are well known. ${ }^{17}$

\section{CONFLICT OF INTEREST}

No potential conflict of interest relevant to this article was reported.

\section{ACKNOWLEDGMENTS}

This study was supported by a grant (2020E330300) of the Korean Disease Control and Prevention Agency funded by the Ministry of Health and Welfare, Republic of Korea.
We thank Ms. So Yeong Kim (EMT) for her assistance with administrative affairs and Mr. Myung Ha Kim for his assistance with literature searches for updating Korean Guidelines for Cardiopulmonary Resuscitation. We also thank the Korean Association of Cardiopulmonary Resuscitation (KACPR) for supporting the process of proofreading.

\section{REFERENCES}

1. Soar J, Berg KM, Andersen LW, et al. Adult advanced life support: 2020 International Consensus on Cardiopulmonary Resuscitation and Emergency Cardiovascular Care Science with Treatment Recommendations. Resuscitation 2020;156:A80119.

2. Panchal AR, Bartos JA, Cabanas JG, et al. Part 3: Adult Basic and Advanced Life Support: 2020 American Heart Association Guidelines for Cardiopulmonary Resuscitation and Emergency Cardiovascular Care. Circulation 2020;142(16_suppl_2): S366-468.

3. Morrison $\sqcup$, Gent LM, Lang E, et al. Part 2: Evidence Evaluation and Management of Conflicts of Interest: 2015 American Heart Association Guidelines Update for Cardiopulmonary Resuscitation and Emergency Cardiovascular Care. Circulation 2015;132(18 Suppl 2):S368-82.

4. Perkins GD, Ji C, Deakin CD, et al. A randomized trial of epinephrine in out-of-hospital cardiac arrest. N Engl J Med 2018;379:711-21.

5. Kudenchuk PJ, Brown SP, Daya M, et al. Amiodarone, lidocaine, or placebo in out-of-hospital cardiac arrest. N Engl J Med 2016;374:1711-22.

6. Benger JR, Kirby K, Black $S$, et al. Effect of a strategy of a supraglottic airway device vs tracheal intubation during out-of-hospital cardiac arrest on functional outcome: the AIRWAYS-2 randomized clinical trial. JAMA 2018;320:77991.

7. Cabanas JG, Myers JB, Williams JG, De Maio VJ, Bachman MW. Double sequential external defibrillation in out-of-hospital refractory ventricular fibrillation: a report of ten cases. Prehosp Emerg Care 2015;19:126-30.

8. Ross EM, Redman T, Harper SA, Mapp JG, Wampler DA, Miramontes DA. Dual defibrillation in out-of-hospital cardiac arrest: a retrospective cohort analysis. Resuscitation 2016; 106:14-7.

9. Cheskes S, Dorian P, Feldman M, et al. Double sequential external defibrillation for refractory ventricular fibrillation: the DOSE VF pilot randomized controlled trial. Resuscitation 2020;150:178-84. 
10. Gaspari R, Weekes A, Adhikari S, et al. Emergency department point-of-care ultrasound in out-of-hospital and in-ED cardiac arrest. Resuscitation 2016;109:33-9.

11. Engel TW 2nd, Thomas C, Medado P, et al. End tidal CO2 and cerebral oximetry for the prediction of return of spontaneous circulation during cardiopulmonary resuscitation. Resuscitation 2019;139:174-81.

12. Singer AJ, Nguyen RT, Ravishankar ST, et al. Cerebral oximetry versus end tidal $\mathrm{CO} 2$ in predicting ROSC after cardiac arrest. Am J Emerg Med 2018;36:403-7.

13. Maharaj R, Raffaele I, Wendon J. Rapid response systems: a systematic review and meta-analysis. Crit Care 2015;19:254.

14. Park Y, Ahn JJ, Kang BJ, et al. Rapid response systems reduce in-hospital cardiopulmonary arrest: a pilot study and motivation for a nationwide survey. Korean J Crit Care Med 2017; 32:231-9.

15. Ko BS, Lim TH, Oh J, et al. The effectiveness of a focused rapid response team on reducing the incidence of cardiac arrest in the general ward. Medicine (Baltimore) 2020;99: e19032.

16. Brady PW, Zix J, Brilli R, et al. Developing and evaluating the success of a family activated medical emergency team: a quality improvement report. BMJ Qual Saf 2015;24:203-11.

17. Smith GB, Prytherch DR, Meredith P, Schmidt PE, Featherstone PI. The ability of the National Early Warning Score (NEWS) to discriminate patients at risk of early cardiac arrest, unanticipated intensive care unit admission, and death. Resuscitation 2013;84:465-70.

18. Subbe CP, Kruger M, Rutherford P, Gemmel L. Validation of a modified Early Warning Score in medical admissions. OMM 2001;94:521-6.

19. Subbe $C P$, Davies RG, Williams $E$, Rutherford $P$, Gemmell $L$. Effect of introducing the Modified Early Warning score on clinical outcomes, cardio-pulmonary arrests and intensive care utilisation in acute medical admissions. Anaesthesia 2003;58:797-802.

20. Edelson DP, Sasson C, Chan PS, et al. Interim Guidance for Basic and Advanced Life Support in Adults, Children, and Neonates With Suspected or Confirmed COVID-19: From the Emergency Cardiovascular Care Committee and Get With The Guidelines-Resuscitation Adult and Pediatric Task Forces of the American Heart Association. Circulation 2020; 141 :e933-43.

21. Korean Society of Emergency Medicine. A recommendation for in-hospital cardiopulmonary resuscitation in patient suspicious of coronavius 19 infection. Seoul: Korean Society of Emergency Medicine; 2020.
22. Crowe $\mathrm{C}$, Bobrow BJ, Vadeboncoeur TF, et al. Measuring and improving cardiopulmonary resuscitation quality inside the emergency department. Resuscitation 2015;93:8-13.

23. Smereka J, Szarpak L, Czekajlo M, et al. The TrueCPR device in the process of teaching cardiopulmonary resuscitation: a randomized simulation trial. Medicine (Baltimore) 2019;98: e15995.

24. Zhou XL, Wang J, Jin XQ, Zhao Y, Liu RL, Jiang C. Quality retention of chest compression after repetitive practices with or without feedback devices: a randomized manikin study. Am J Emerg Med 2020;38:73-8.

25. Oh J, Lim TH, Cho $Y$, et al. Training a chest compression of 6-7 cm depth for high quality cardiopulmonary resuscitation in hospital setting: a randomised controlled trial. Yonsei Med J 2016;57:505-11.

26. Lee $\mathrm{S}, \mathrm{Oh} J$, Kang $\mathrm{H}$, et al. Proper target depth of an accelerometer-based feedback device during CPR performed on a hospital bed: a randomized simulation study. Am J Emerg Med 2015;33:1425-9.

27. Neumar RW, Otto CW, Link MS, et al. Part 8: adult advanced cardiovascular life support: 2010 American Heart Association Guidelines for Cardiopulmonary Resuscitation and Emergency Cardiovascular Care. Circulation 2010;122(18 Suppl 3):S729-67.

28. Ochoa FJ, Ramalle-Gomara E, Carpintero JM, Garcia A, Saralegui I. Competence of health professionals to check the carotid pulse. Resuscitation 1998;37:173-5.

29. Mather C, O'Kelly S. The palpation of pulses. Anaesthesia 1996;51:189-91.

30. Levine RL, Wayne MA, Miller CC. End-tidal carbon dioxide and outcome of out-of-hospital cardiac arrest. N Engl J Med 1997;337:301-6.

31. Pearce AK, Davis DP, Minokadeh A, Sell RE. Initial end-tidal carbon dioxide as a prognostic indicator for inpatient PEA arrest. Resuscitation 2015;92:77-81.

32. Ahrens T, Schallom L, Bettorf $K$, et al. End-tidal carbon dioxide measurements as a prognostic indicator of outcome in cardiac arrest. Am J Crit Care 2001;10:391-8.

33. Sandroni C, De Santis P, D'Arrigo S. Capnography during cardiac arrest. Resuscitation 2018;132:73-7.

34. Paiva EF, Paxton JH, O'Neil BJ. The use of end-tidal carbon dioxide (ETCO2) measurement to guide management of cardiac arrest: a systematic review. Resuscitation 2018;123:1-7.

35. Grmec S. Comparison of three different methods to confirm tracheal tube placement in emergency intubation. Intensive Care Med 2002;28:701-4.

36. Reynolds JC, Salcido DD, Menegazzi JJ. Coronary perfusion 
pressure and return of spontaneous circulation after prolonged cardiac arrest. Prehosp Emerg Care 2010;14:78-84.

37. Rivers EP, Martin GB, Smithline $H$, et al. The clinical implications of continuous central venous oxygen saturation during human CPR. Ann Emerg Med 1992;21:1094-101.

38. Cournoyer $A$, Iseppon $M$, Chauny JM, Denault $A$, Cossette $S$, Notebaert E. Near-infrared spectroscopy monitoring during cardiac arrest: a systematic review and meta-analysis. Acad Emerg Med 2016;23:851-62.

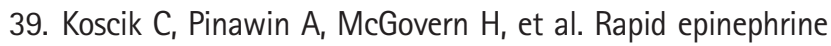
administration improves early outcomes in out-of-hospital cardiac arrest. Resuscitation 2013;84:915-20.

40. Feinstein BA, Stubbs BA, Rea T, Kudenchuk PJ. Intraosseous compared to intravenous drug resuscitation in out-of-hospital cardiac arrest. Resuscitation 2017;117:91-6.

41. Aitkenhead AR. Drug administration during CPR: what route? Resuscitation 1991;22:191-5.

42. Orlowski JP, Porembka DT, Gallagher JM, Lockrem JD, VanLente F. Comparison study of intraosseous, central intravenous, and peripheral intravenous infusions of emergency drugs. Am J Dis Child 1990;144:112-7.

43. Kawano T, Grunau B, Scheuermeyer FX, et al. Intraosseous vascular access is associated with lower survival and neurologic recovery among patients with out-of-hospital cardiac arrest. Ann Emerg Med 2018;71:588-96.

44. Barsan WG, Levy RC, Weir H. Lidocaine levels during CPR: differences after peripheral venous, central venous, and intracardiac injections. Ann Emerg Med 1981;10:73-8.

45. Kuhn GJ, White BC, Swetnam RE, et al. Peripheral vs central circulation times during CPR: a pilot study. Ann Emerg Med 1981;10:417-9.

46. Emerman CL, Pinchak AC, Hancock D, Hagen JF. Effect of injection site on circulation times during cardiac arrest. Crit Care Med 1988;16:1138-41.

47. Hornchen U, Schuttler J, Stoeckel H, Eichelkraut W, Hahn N. Endobronchial instillation of epinephrine during cardiopulmonary resuscitation. Crit Care Med 1987;15:1037-9.

48. Niemann JT, Stratton SJ, Cruz B, Lewis RJ. Endotracheal drug administration during out-of-hospital resuscitation: where are the survivors? Resuscitation 2002;53:153-7.

49. Callaham M, Madsen CD, Barton CW, Saunders CE, Pointer J. A randomized clinical trial of high-dose epinephrine and norepinephrine vs standard-dose epinephrine in prehospital cardiac arrest. JAMA 1992;268:2667-72.

50. Finn J, Jacobs I, Williams TA, Gates S, Perkins GD. Adrenaline and vasopressin for cardiac arrest. Cochrane Database Syst Rev 2019;1:CD003179.
51. Holmberg MJ, Issa MS, Moskowitz A, et al. Vasopressors during adult cardiac arrest: a systematic review and meta-analysis. Resuscitation 2019;139:106-21.

52. Stiell IG, Hebert PC, Wells GA, et al. Vasopressin versus epinephrine for inhospital cardiac arrest: a randomized controlled trial. Lancet 2001;358:105-9.

53. Aung $\mathrm{K}_{1}$ Htay T. Vasopressin for cardiac arrest: a systematic review and meta-analysis. Arch Intern Med 2005;165:1724.

54. Callaway CW, Hostler D, Doshi AA, et al. Usefulness of vasopressin administered with epinephrine during out-of-hospital cardiac arrest. Am J Cardiol 2006;98:1316-21.

55. Gueugniaud PY, David JS, Chanzy E, et al. Vasopressin and epinephrine vs. epinephrine alone in cardiopulmonary resuscitation. N Engl J Med 2008;359:21-30.

56. Mukoyama T, Kinoshita K, Nagao K, Tanjoh K. Reduced effectiveness of vasopressin in repeated doses for patients undergoing prolonged cardiopulmonary resuscitation. Resuscitation 2009;80:755-61.

57. Panchal AR, Berg KM, Kudenchuk PJ, et al. 2018 American Heart Association Focused Update on Advanced Cardiovascular Life Support Use of Antiarrhythmic Drugs During and Immediately After Cardiac Arrest: An Update to the American Heart Association Guidelines for Cardiopulmonary Resuscitation and Emergency Cardiovascular Care. Circulation 2018;138:e740-9.

58. Soar J, Nolan JP, Bottiger BW, et al. European Resuscitation Council Guidelines for Resuscitation 2015: Section 3. Adult advanced life support. Resuscitation 2015;95:100-47.

59. Skrifvars MB, Pettila V, Rosenberg PH, Castren M. A multiple logistic regression analysis of in-hospital factors related to survival at six months in patients resuscitated from out-ofhospital ventricular fibrillation. Resuscitation 2003;59:31928.

60. Kudenchuk PJ, Newell C, White L, Fahrenbruch C, Rea T, Eisenberg M. Prophylactic lidocaine for post resuscitation care of patients with out-of-hospital ventricular fibrillation cardiac arrest. Resuscitation 2013;84:1512-8.

61. Bircher NG, Chan PS, Xu Y; American Heart Association's Get With The Guidelines-Resuscitation Investigators. Delays in cardiopulmonary resuscitation, defibrillation, and epinephrine administration all decrease survival in in-hospital cardiac arrest. Anesthesiology 2019;130:414-22.

62. Valenzuela TD, Roe DJ, Nichol G, Clark LL, Spaite DW, Hardman RG. Outcomes of rapid defibrillation by security officers after cardiac arrest in casinos. N Engl J Med 2000;343:1206-9.

63. White RD, Asplin BR, Bugliosi TF, Hankins DG. High discharge 
survival rate after out-of-hospital ventricular fibrillation with rapid defibrillation by police and paramedics. Ann Emerg Med 1996;28:480-5.

64. Meier $P$, Baker $P$, Jost $D$, et al. Chest compressions before defibrillation for out-of-hospital cardiac arrest: a meta-analysis of randomized controlled clinical trials. BMC Med 2010; 8:52.

65. Huang Y, He Q, Yang $\sqcup$, Liu GJ, Jones A. Cardiopulmonary resuscitation (CPR) plus delayed defibrillation versus immediate defibrillation for out-of-hospital cardiac arrest. Cochrane Database Syst Rev 2014;2014:CD009803.

66. Martens PR, Russell JK, Wolcke B, et al. Optimal Response to Cardiac Arrest study: defibrillation waveform effects. Resuscitation 2001;49:233-43.

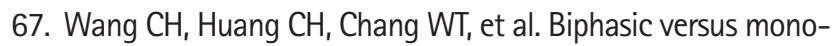
phasic defibrillation in out-of-hospital cardiac arrest: a systematic review and meta-analysis. Am J Emerg Med 2013; 31:1472-8.

68. Jost $D$, Degrange $H$, Verret $C$, et al. DEFI 2005: a randomized controlled trial of the effect of automated external defibrillator cardiopulmonary resuscitation protocol on outcome from out-of-hospital cardiac arrest. Circulation 2010;121: 1614-22.

69. Berdowski J, ten Haaf M, Tijssen JG, Chapman FW, Koster RW. Time in recurrent ventricular fibrillation and survival after out-of-hospital cardiac arrest. Circulation 2010;122: 1101-8.

70. Edelson DP, Abella BS, Kramer-Johansen J, et al. Effects of compression depth and pre-shock pauses predict defibrillation failure during cardiac arrest. Resuscitation 2006;71: 137-45.

71. Cheskes S, Schmicker RH, Christenson J, et al. Perishock pause: an independent predictor of survival from out-of-hospital shockable cardiac arrest. Circulation 2011;124:58-66.

72. Cheskes $S$, Schmicker RH, Verbeek PR, et al. The impact of peri-shock pause on survival from out-of-hospital shockable cardiac arrest during the Resuscitation Outcomes Consortium PRIMED trial. Resuscitation 2014;85:336-42.

73. Sell RE, Sarno R, Lawrence B, et al. Minimizing pre- and postdefibrillation pauses increases the likelihood of return of spontaneous circulation (ROSC). Resuscitation 2010;81:822-5.

74. Deakin CD, McLaren RM, Petley GW, Clewlow F, DalrympleHay MJ. Effects of positive end-expiratory pressure on transthoracic impedance: implications for defibrillation. Resuscitation 1998;37:9-12.

75. Kerber RE, Grayzel J, Hoyt R, Marcus M, Kennedy J. Transthoracic resistance in human defibrillation: influence of body weight, chest size, serial shocks, paddle size and paddle contact pressure. Circulation 1981;63:676-82.

76. Connell PN, Ewy GA, Dahl CF, Ewy MD. Transthoracic impedance to defibrillator discharge: effect of electrode size and electrode-chest wall interface. J Electrocardiol 1973;6:313M.

77. Kim HE, Lee KJ, Jo YH, et al. Refractory ventricular fibrillation treated with double simultaneous defibrillation: pilot study. Emerg Med Int 2020;2020:5470912.

78. Chung SP, Sakamoto T, Lim SH, et al. The 2015 Resuscitation Council of Asia (RCA) guidelines on adult basic life support for lay rescuers. Resuscitation 2016;105:145-8.

79. Wang HE, Schmicker RH, Daya MR, et al. Effect of a strategy of initial laryngeal tube insertion vs endotracheal intubation on 72-hour survival in adults with out-of-hospital cardiac arrest: a randomized clinical trial. JAMA 2018;320:769-78.

80. Jabre $P$, Penaloza A, Pinero $D$, et al. Effect of bag-mask ventilation vs endotracheal intubation during cardiopulmonary resuscitation on neurological outcome after out-of-hospital cardiorespiratory arrest: a randomized clinical trial. JAMA 2018;319:779-87.

81. Andersen LW, Holmberg MJ, Berg KM, Donnino MW, Granfeldt A. In-hospital cardiac arrest: a review. JAMA 2019;321: 1200-10.

82. Soar J, Maconochie I, Wyckoff MH, et al. 2019 International Consensus on Cardiopulmonary Resuscitation and Emergency Cardiovascular Care Science With Treatment Recommendations: Summary From the Basic Life Support; Advanced Life Support; Pediatric Life Support; Neonatal Life Support; Education, Implementation, and Teams; and First Aid Task Forces. Circulation 2019;140:e826-80.

83. Andersen LW, Granfeldt A, Callaway CW, et al. Association between tracheal intubation during adult in-hospital cardiac arrest and survival. JAMA 2017;317:494-506.

84. Perkins GD, Lall R, Quinn T, et al. Mechanical versus manual chest compression for out-of-hospital cardiac arrest (PARAMEDIC): a pragmatic, cluster randomised controlled trial. Lancet 2015;385:947-55.

85. Rubertsson $S$, Lindgren $E$, Smekal $D$, et al. Mechanical chest compressions and simultaneous defibrillation vs conventional cardiopulmonary resuscitation in out-of-hospital cardiac arrest: the LINC randomized trial. JAMA 2014;311:5361.

86. Wang HC, Chiang WC, Chen SY, et al. Video-recording and time-motion analyses of manual versus mechanical cardiopulmonary resuscitation during ambulance transport. Resuscitation 2007;74:453-60. 
87. Hallstrom A, Rea TD, Sayre MR, et al. Manual chest compression vs use of an automated chest compression device during resuscitation following out-of-hospital cardiac arrest: a randomized trial. JAMA 2006;295:2620-8.

88. Paradis NA, Young G, Lemeshow S, Brewer JE, Halperin HR. Inhomogeneity and temporal effects in AutoPulse Assisted Prehospital International Resuscitation: an exception from consent trial terminated early. Am J Emerg Med 2010;28: 391-8.

89. Tomte 0 , Sunde $K$, Lorem $T$, et al. Advanced life support performance with manual and mechanical chest compressions in a randomized, multicentre manikin study. Resuscitation 2009;80:1152-7.

90. Wik $L$, Olsen JA, Persse $D$, et al. Manual vs. integrated automatic load-distributing band CPR with equal survival after out of hospital cardiac arrest: the randomized CIRC trial. Resuscitation 2014;85:741-8.

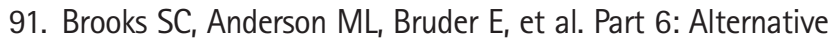
Techniques and Ancillary Devices for Cardiopulmonary Resuscitation: 2015 American Heart Association Guidelines Update for Cardiopulmonary Resuscitation and Emergency Cardiovascular Care. Circulation 2015;132(18 Suppl 2):S43643.

92. Panchal AR, Berg KM, Hirsch KG, et al. 2019 American Heart Association Focused Update on Advanced Cardiovascular Life Support: Use of Advanced Airways, Vasopressors, and Extracorporeal Cardiopulmonary Resuscitation During Cardiac Arrest: An Update to the American Heart Association Guidelines for Cardiopulmonary Resuscitation and Emergency Cardiovascular Care. Circulation 2019;140:e881-94.

93. Holmberg MJ, Geri G, Wiberg S, et al. Extracorporeal cardiopulmonary resuscitation for cardiac arrest: a systematic review. Resuscitation 2018;131:91-100.

94. Bartos JA, Grunau B, Carlson C, et al. Improved survival with extracorporeal cardiopulmonary resuscitation despite progressive metabolic derangement associated with prolonged resuscitation. Circulation 2020;141:877-86.

95. Cesana F, Avalli L, Garatti L, et al. Effects of extracorporeal cardiopulmonary resuscitation on neurological and cardiac outcome after ischaemic refractory cardiac arrest. Eur Heart J Acute Cardiovasc Care 2018;7:432-41.

96. Choi DH, Kim YJ, Ryoo SM, et al. Extracorporeal cardiopulmonary resuscitation among patients with out-of-hospital cardiac arrest. Clin Exp Emerg Med 2016;3:132-8.

97. Han KS, Kim SJ, Lee EJ, Lee SW. The effect of extracorporeal cardiopulmonary resuscitation in re-arrest after survival event: a retrospective analysis. Perfusion 2020;35:39-47.
98. Hase M, Tsuchihashi $K_{1}$ Fujii $N$, et al. Early defibrillation and circulatory support can provide better long-term outcomes through favorable neurological recovery in patients with out-of-hospital cardiac arrest of cardiac origin. Circ J 2005; 69:1302-7.

99. Kim SJ, Jung JS, Park JH, Park JS, Hong YS, Lee SW. An optimal transition time to extracorporeal cardiopulmonary resuscitation for predicting good neurological outcome in patients with out-of-hospital cardiac arrest: a propensity-matched study. Crit Care 2014;18:535.

100. Maekawa K, Tanno K, Hase M, Mori K, Asai Y. Extracorporeal cardiopulmonary resuscitation for patients with out-of-hospital cardiac arrest of cardiac origin: a propensity-matched study and predictor analysis. Crit Care Med 2013;41:118696.

101. Mandigers L, Scholten E, Rietdijk WJ, et al. Survival and neurological outcome with extracorporeal cardiopulmonary resuscitation for refractory cardiac arrest caused by massive pulmonary embolism: a two center observational study. Resuscitation 2019;136:8-13.

102. Matsuoka Y, Ikenoue T, Hata N, et al. Hospitals' extracorporeal cardiopulmonary resuscitation capabilities and outcomes in out-of-hospital cardiac arrest: a population-based study. Resuscitation 2019;136:85-92.

103. Siao FY, Chiu CC, Chiu CW, et al. Managing cardiac arrest with refractory ventricular fibrillation in the emergency department: conventional cardiopulmonary resuscitation versus extracorporeal cardiopulmonary resuscitation. Resuscitation 2015;92:70-6.

104. Venturini JM, Retzer E, Estrada JR, et al. Mechanical chest compressions improve rate of return of spontaneous circulation and allow for initiation of percutaneous circulatory support during cardiac arrest in the cardiac catheterization laboratory. Resuscitation 2017;115:56-60.

105. Yannopoulos D, Bartos JA, Raveendran G, et al. Coronary artery disease in patients with out-of-hospital refractory ventricular fibrillation cardiac arrest. J Am Coll Cardiol 2017;70: 1109-17.

106. Chen YS, Lin JW, Yu HY, et al. Cardiopulmonary resuscitation with assisted extracorporeal life-support versus conventional cardiopulmonary resuscitation in adults with in-hospital cardiac arrest: an observational study and propensity analysis. Lancet 2008;372:554-61.

107. Lin JW, Wang MJ, Yu HY, et al. Comparing the survival between extracorporeal rescue and conventional resuscitation in adult in-hospital cardiac arrests: propensity analysis of three-year data. Resuscitation 2010;81:796-803. 
108. Spindelboeck W, Gemes G, Strasser $C_{\text {, et al. Arterial blood }}$ gases during and their dynamic changes after cardiopulmonary resuscitation: a prospective clinical study. Resuscitation 2016;106:24-9.

109. Young $P$, Bailey $M$, Bellomo $R$, et al. HyperOxic Therapy OR Norm0xic Therapy after out-of-hospital cardiac arrest (HOT OR NOT): a randomised controlled feasibility trial. Resuscitation 2014;85:1686-91.

110. Jakkula $P$, Reinikainen $M$, Hastbacka J, et al. Targeting two different levels of both arterial carbon dioxide and arterial oxygen after cardiac arrest and resuscitation: a randomised pilot trial. Intensive Care Med 2018;44:2112-21.

111. ICU-ROX Investigators and the Australian and New Zealand Intensive Care Society Clinical Trials Group, Mackle D, Bellomo $R$, et al. Conservative oxygen therapy during mechanical ventilation in the ICU. N Engl J Med 2020;382:989-98.

112. Levin PD, Pizov R. End-tidal carbon dioxide and outcome of out-of-hospital cardiac arrest. N Engl J Med 1997;337:1694-5.

113. Clattenburg EJ, Wroe P, Brown $S$, et al. Point-of-care ultrasound use in patients with cardiac arrest is associated prolonged cardiopulmonary resuscitation pauses: a prospective cohort study. Resuscitation 2018;122:65-8.

114. Chardoli M, Heidari F, Rabiee H, Sharif-Alhoseini M, Shokoohi H, Rahimi-Movaghar V. Echocardiography integrated ACLS protocol versus conventional cardiopulmonary resuscitation in patients with pulseless electrical activity cardiac arrest. Chin J Traumatol 2012;15:284-7.

115. Breitkreutz $R$, Price $S$, Steiger HV, et al. Focused echocardiographic evaluation in life support and peri-resuscitation of emergency patients: a prospective trial. Resuscitation 2010; 81:1527-33.

116. Chou HC, Chong KM, Sim SS, et al. Real-time tracheal ultrasonography for confirmation of endotracheal tube placement during cardiopulmonary resuscitation. Resuscitation 2013;84:1708-12.

117. Konstantinides SV, Meyer G, Becattini C, et al. 2019 ESC Guidelines for the diagnosis and management of acute pulmonary embolism developed in collaboration with the European Respiratory Society (ERS): the Task Force for the diagnosis and management of acute pulmonary embolism of the European Society of Cardiology (ESC). Eur Respir J 2019;54: 1901647.

118. Bottiger BW, Arntz HR, Chamberlain DA, et al. Thrombolysis during resuscitation for out-of-hospital cardiac arrest. N Engl J Med 2008;359:2651-62.

119. Javaudin F, Lascarrou JB, Le Bastard $\mathrm{Q}$, et al. Thrombolysis during resuscitation for out-of-hospital cardiac arrest caused by pulmonary embolism increases 30-day survival: findings from the French National Cardiac Arrest Registry. Chest 2019; 156:1167-75.

120. Yousuf T, Brinton T, Ahmed K, et al. Tissue plasminogen activator use in cardiac arrest secondary to fulminant pulmonary embolism. J Clin Med Res 2016;8:190-5.

121. Fava $M$, Loyola $S$, Bertoni $H$, Dougnac A. Massive pulmonary embolism: percutaneous mechanical thrombectomy during cardiopulmonary resuscitation. J Vasc Interv Radiol 2005; 16:119-23.

122. Chesnutt AN. Physiology of normal pregnancy. Crit Care Clin 2004;20:609-15.

123. Humphries A, Mirjalili SA, Tarr GP, Thompson JM, Stone P. The effect of supine positioning on maternal hemodynamics during late pregnancy. J Matern Fetal Neonatal Med 2019; 32:3923-30.

124. Kundra P, Khanna S, Habeebullah S, Ravishankar M. Manual displacement of the uterus during Caesarean section. Anaesthesia 2007;62:460-5.

125. Holmes S, Kirkpatrick ID, Zelop CM, Jassal DS. MRI evaluation of maternal cardiac displacement in pregnancy: implications for cardiopulmonary resuscitation. Am J Obstet Gynecol 2015;213:401.

126. Delgado C, Dawson $K$, Schwaegler $B$, Zachariah $R$, Einav $S$, Bollag L. Hand placement during chest compressions in parturients: a pilot study to identify the location of the left ventricle using transthoracic echocardiography. Int J Obstet Anesth 2020;43:31-5.

127. Einav S, Kaufman N, Sela HY. Maternal cardiac arrest and perimortem caesarean delivery: evidence or expert-based? Resuscitation 2012;83:1191-200.

128. Beckett VA, Knight M, Sharpe P. The CAPS Study: incidence, management and outcomes of cardiac arrest in pregnancy in the UK: a prospective, descriptive study. BJOG 2017;124: 1374-81.

129. Chan PS, Krumholz HM, Nichol G, Nallamothu BK; American Heart Association National Registry of Cardiopulmonary Resuscitation Investigators. Delayed time to defibrillation after in-hospital cardiac arrest. N Engl J Med 2008;358:9-17.

130. Kang JY, Kim YJ, Shin YJ, Huh JW, Hong SB, Kim WY. Association between time to defibrillation and neurologic outcome in patients with in-hospital cardiac arrest. Am J Med Sci 2019;358:143-8.

131. Patel KK, Spertus JA, Khariton $Y$, et al. Association between prompt defibrillation and epinephrine treatment with longterm survival after in-hospital cardiac arrest. Circulation 2018;137:2041-51. 
132. Hessulf $F$, Karlsson $T$, Lundgren $P$, et al. Factors of importance to 30-day survival after in-hospital cardiac arrest in Sweden: a population-based register study of more than 18,000 cases. Int J Cardiol 2018;255:237-42.
133. Nolan JP, Soar J, Smith GB, et al. Incidence and outcome of in-hospital cardiac arrest in the United Kingdom National Cardiac Arrest Audit. Resuscitation 2014;85:987-92. 